\title{
Science has much to offer social movements in the face of planetary emergencies
}

To the Editor - Ecologists Gardner and Wordley ${ }^{1}$ recently argued that in the face of "interconnected planetary emergencies threatening our climate and ecosystems," information on the severity and urgency of the problem is insufficient to promote the necessary social and political change. Thus, "scientists should join civil disobedience movements to fight these unprecedented crises". That the realization that facts alone may be insufficient is only now making headlines in the context of climate change is not the fault of the authors, but rather symptomatic of a long-standing disconnect between the natural and social sciences ${ }^{2}$. While we support their ambitions, we argue that Gardner and Wordley neglect one of the most important, powerful and unique avenues for scientists to contribute to social movements - that is, with our arduously accumulated knowledge about processes of social and political change.

We agree that scientists can reasonably partake in social mobilization and admire the authors' refutation of arguments about the 'proper channels' of scientific influence and the effects of activism on credibility. However, when it comes to how our knowledge can contribute to social movements, Gardner and Wordley only hint in passing: scientists can "ensure all members of civil disobedience groups are well versed in climate science, ecology and other relevant disciplines".

First, we suggest that focus should be on social movements more broadly rather than civil disobedience specifically, as the latter is only one possible tactic among many available to movement participants ${ }^{3}$. Second, it is essential to note that the 'relevant disciplines' most definitely include many in the social sciences, including the impressive research focusing on social movements and contentious politics ${ }^{4,5}$.

As we see it, not only do scientists have much to contribute when it comes to explaining problems like climate change, but also they can contribute to developing viable alternatives in the form of, inter alia, institutional arrangements and technologies. Moreover, social scientists analyse the mechanisms of social change and the dynamics of economic and political systems ${ }^{6}$. For social movements strategizing and planning their activities, access to such knowledge may be crucial to better inform the development of: tactics that produce desirable outcomes, sustainable strategies for action (including appropriate targets and if, when and how civil disobedience is likely to produce desirable outcomes), effective problem framings and strategic alliance building. In the face of a problem as complex as climate change, the better movements understand the social systems they hope to impact, the more effective they have a chance to be.

Whether scientific contributions are best made from a position 'within' or 'outside' movements is an important question and depends on the scientist, movement and cultural context in question. There are also inevitable limits to scientific knowledge; other forms of knowledge - derived from practical experience, social interaction and deep contextual embeddedness - are crucial for social movements and may have greater influence on their evolution and outcomes. The integration of different forms of knowledge is a complex issue that requires careful conceptualization. To complement Gardner and Wordley's call to action, we urge for development of better platforms that allow scientists to fruitfully interact with activists and social movement organizations to inform, stimulate and critically challenge their efforts in solving planetary emergencies.

\section{Ellinor Isgren (D)*, Chad S. Boda, David Harnesk (D) and David O'Byrne \\ Lund University Centre for Sustainability Studies, Lund, Sweden. \\ *e-mail:ellinor.isgren@lucsus.lu.se}

Published online: 28 October 2019

https://doi.org/10.1038/s41559-019-1024-X

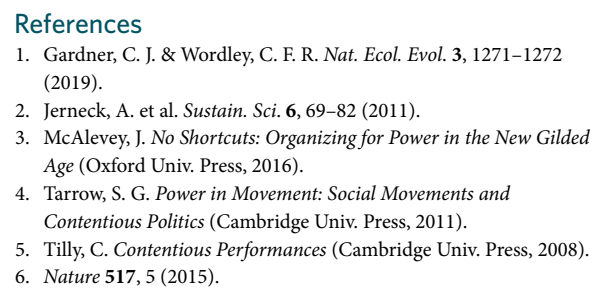

Acknowledgements

We thank the Pufendorf Institute for Advanced Studies at Lund University for supporting the advanced study group CIVICSUS (2018-19).

Competing interests

The authors declare no competing interests. 